\title{
In vitro isolation of circulating endothelial progenitor cells is related to the high density lipoprotein plasma levels
}

\author{
FABIO PELLEGATTA ${ }^{1}$, MARTA BRAGHERI ${ }^{1}$, LILIANA GRIGORE ${ }^{2}$, SARA RASELLI $^{2}$, \\ FRANCO MARIA MAGGI ${ }^{2}$, CLAUDIA BRAMBILLA ${ }^{1}$, ALICE REDUZZI ${ }^{1}$, ANGELA PIRILLO ${ }^{1}$, \\ GIUSEPPE DANILO NORATA ${ }^{1}$ and ALBERICO LUIGI CATAPANO ${ }^{1,2}$ \\ ${ }^{1}$ Department of Pharmacological Sciences, University of Milan, via Balzaretti 9, I-20132 Milan; \\ ${ }^{2}$ Centro per lo Studio e la Prevenzione delle Vasculopatie Aterosclerotiche, Ospedale Bassini, Cinisello Balsamo, Italy
}

Received August 30, 2005; Accepted October 17, 2005

\begin{abstract}
Circulating endothelial progenitor cells (EPCs) play an important role in post natal neovascularization. High density lipoproteins (HDL) protect the vascular wall from atherosclerosis. The role exerted by HDL on EPCs physiology is unknown. In this study we investigated whether the levels of plasma HDL can modulate the number of EPCs. The number of EPCs was evaluated in 24 subjects as the number of endothelial colony-forming unit (e-CFU) growth in culture. The number of AC133 positive progenitor cells present in the gate of the CD34 bright positive lymphocytes was also evaluated. Plasma levels of HDL, triglycerides and total cholesterol/HDL cholesterol ratio correlated with the number of e-CFU ( $\mathrm{r}=0.62, \mathrm{P}=0.006 ; \mathrm{r}=-0.54, \mathrm{P}=0.019$, and $\mathrm{r}=-0.61, \mathrm{P}=0.007$ respectively), but not with the number of $\mathrm{CD} 34 / \mathrm{AC} 133$ positive progenitor cells. In vitro, the incubation of the mononuclear cellular fraction with HDL did not increase the number of e-CFU in culture, whereas LDL and VLDL reduced the number of e-CFU. Our results indicate that human HDL plasma levels directly relate to the number of circulating endothelial progenitor cells that can be isolated in vitro, as determined by the number of e-CFU.
\end{abstract}

\section{Introduction}

Circulating endothelial precursor cells (EPCs) are present in the blood and play a key role in the re-constitution of the vessel wall (1). Infusion of bone marrow cells or mononuclear cells in patients with myocardial infarction ameliorates cardiac perfusion, indicating that these cellular fractions contain vascular precursors (2). EPCs physiology and the identification of factors modulating their number and/or activity are currently under intensive investigation (3).

Correspondence to: Dr Alberico Luigi Catapano, Department of Pharmacological Sciences, University of Milan, via Balzaretti 9, I-20132 Milan, Italy

E-mail: alberico.catapano@unimi.it

Key words: circulating progenitor cells, lipoproteins, angiogenesis, stem cells, vascular biology
EPCs derive from bone marrow and are released in the blood after cytokine stimulation. Ischemic tissues release vascular endothelial growth factor (VEGF) that in turn stimulates EPCs release (3).

Clinical conditions characterized by accelerated atherosclerosis are associated with an impaired EPCs plasma number and differentiation in vitro. In particular, several of the risk factors for cardiovascular disease relate to the number of eCFU that can be isolated (4-10). The role exerted by plasma lipoproteins on EPCs physiology has only partially been investigated $(4,5,11)$. Plasma lipoprotein levels are amongst the strongest risk factors for cardiovascular disease as LDL directly correlate to the risk of coronary heart disease (12) and HDL cholesterol levels are inversely related to it (13). As for the role of plasma lipoproteins in determining EPCs levels, few studies are available and mixed findings have been reported. While some studies have detected a detrimental effect of hypercholesterolemia and LDL plasma levels on EPCs physiology, the effect of HDL and VLDL is unclear. In the present work, we addressed the question of whether, in subjects without any overt vascular disease, plasma lipoprotein levels relate to the number of circulating EPCs.

\section{Patients and methods}

Characteristics of study patients and healthy controls. Twenty-four patients were enrolled in this study. Subjects were excluded from the study if they had known inflammatory or malignant diseases, coronary artery disease, or myocardial infarction. Women were excluded because of the possible effects of the menstrual cycle on angiogenesis. None of the patients had previously been treated with statin or any other lipid lowering therapy, neither were taking vitamins, ACE inhibitors or antidiabetic drugs. Informed consent was obtained, according to the rules of the Ethics Committee of our centre. Plasma lipids were determined by routine laboratory procedures on plasma isolated after a $14-\mathrm{h}$ fasting.

EPC culture assay. EPC culture assay was performed according to the method described by Hill et al (5). Briefly, mononuclear cells were isolated by density-gradient centrifugation with Biocoll (Biochrom AG) from $20 \mathrm{ml}$ of peripheral blood obtained after an overnight fast. Immediately after isolation, 
$10^{7}$ mononuclear cells were plated in 6-well culture dishes coated with human fibronectin (Sigma) and maintained in medium 199 supplemented with 20\% FCS for $24 \mathrm{~h}$ to allow circulating endothelial cells adhesion. After 24-h non-adherent mononuclear cells were retrieved and plated in 24-well culture dishes at $10^{6}$ cells for dish. Medium was changed at $3 \mathrm{rd}$, 5th and 7 th day of culture.

After 7 days the clusters presenting cells sprouting were identified as e-CFU. Three different investigators counted the number of e-CFU present in 6 different dishes, in a blinded fashion. The reproducibility of e-CFU count was assessed analyzing the number of e-CFU in the same subject at least one week apart $(n=6)$. The correlation observed was 0.92 . Intra assay correlation was 0.93 .

Lipoprotein isolation. Human $\mathrm{HDL}_{3}(\mathrm{~d}=1.125-1.21 \mathrm{~g} / \mathrm{ml})$, VLDL ( $\mathrm{d}=1.006-1.019)$ and LDL $(\mathrm{d}=1.019-1.063)$ were isolated from fresh plasma of fasting normolipidemic healthy volunteers by sequential ultracentrifugation (14), dialyzed against PBS containing $0.01 \%$ EDTA and sterile filtered by passage through a $0.45 \mu \mathrm{m}$ filter. Lipoprotein protein content was determined by the method of Lowry using BSA as standard (15).

Characterization of e-CFU cells. To detect the uptake of 1,1'dioctadecyl-3,3,3',3'-tetramethylin-docarbocyanine-labeled acetylated-LDL, cells were incubated with DiO-AcLDL $(2.4 \mu \mathrm{g} / \mathrm{ml})(16)$ at $37^{\circ} \mathrm{C}$ for $1 \mathrm{~h}$, then fixed with $2 \%$ paraformaldehyde for $10 \mathrm{~min}$. Lectin staining was performed by incubation with fluorescein isothiocyanate (FITC)-labeled Ulex Europeus agglutinin I (lectin, $10 \mu \mathrm{g} / \mathrm{ml}$; Sigma) for $1 \mathrm{~h}$. After staining, samples were viewed with a fluorescence microscope (Zeiss).

To detect the expression of other endothelial markers, e-CFU cells were detached with $1 \mathrm{mmol} / \mathrm{l}$ EDTA in PBS. Cells were incubated for 15 min with monoclonal antibodies against human kinase insert domain receptor (KDR; Sigma), human vascular endothelium-cadherin (Becton Dickinson), endothelial nitric oxide synthase (eNOS/NOS3; Santa Cruz), CD31 (clone H89D3 a kind gift of Dr M. Zocchi) followed by an appropriate FITC-labeled secondary antibody. Positive cells were evaluated using a fluorescence-activated cell sorter (FACScan flow cytometer; Beckton Dickinson).

To analyse the expression of specific vascular genes, total RNA was extracted and underwent reverse transcription according to standard procedures. cDNA $(3 \mu 1)$ was amplified by real-time quantitative PCR with $1 \mathrm{X}$ SYBER Green universal PCR mastermix (Bio-Rad). The specificity of the SYBER Green fluorescence was tested by plotting fluorescence as a function of temperature to generate a melting curve of the amplicon. The melting peaks of the amplicons were as expected. The primers used were: Flt-1, sense 5'-CCC CGCCCCCAGACTA-3' and antisense 5'-AAGGCTTCGT GTCAAACTCTAGATG-3'; Tie-1, sense 5'-CACTCCAGC TCCTTCGCTTAA-3' and antisense 5'-CGGGAGTGGGAG TAGCTGAA-3'; Tie-2, sense 5'-TGGCGCCCCCATGAG-3' and antisense 5'-GGATCCTGGTGCTGGTTCATT-3'; VEcadherin, sense 5'-AAAGTTCATGACGTGAACGACAA-3' and antisense 5'-GCACGGACGCATTGAACA-3'; AC133, sense 5'-AGCGATCAAGGACAAAGAG-3' and antisense
Table I. Patient characteristics.

\begin{tabular}{lcc}
\hline Variable & Mean \pm SD & Range \\
\hline Age (years) & $60.9 \pm 9.1$ & $46-78$ \\
BMI & $27.7 \pm 3.3$ & $23.4-35.4$ \\
P.A.S. (mmHg) & $134.8 \pm 13.8$ & $120-160$ \\
P.A.D. (mmHg) & $83.7 \pm 8.2$ & $70-100$ \\
Total cholesterol (mmol/l) & $5.4 \pm 0.78$ & $3.25-7.68$ \\
LDL (mmol/l) & $3.18 \pm 0.778$ & $1.7-4.61$ \\
HDL (mmol/l) & $1.36 \pm 0.37$ & $0.77-2.35$ \\
Triglycerides (mmol/l) & $1.8 \pm 1.3$ & $0.6-4.9$ \\
Total cholesterol/HDL cholesterol & $4.2 \pm 1.5$ & $2.4-7.9$ \\
Plasma glucose (mg/dl) & $99.6 \pm 24.4$ & $78-189$ \\
Global cardiovascular risk & $20.3 \pm 12.8$ & $2-36.3$ \\
(10 years) & & \\
\hline
\end{tabular}

BMI, body mass index; P.A.S., systolic arterial pressure; P.A.D., diastolic arterial pressure.

5'-TGTGTACTTTGTTGCAAGCT-3'; eNOS, sense 5'-CT CGTCCCTGTGGAAAGACAA-3' and antisense 5'-TGAC TTTGGCTAGCTGGTAACTGT-3'; KDR/Flk-1, sense 5'-TC AGGCAGCTCACAGTCCTAGA-3' and antisense 5'-ACTT GTCGTCTGATTCTCCAGGTT-3'; CD31/PECAM, sense 5'-CCCAGTTTGAGGTCATAAAAGGA-3' and antisense 5'-AGGCAAAGTTCCACTGATCGA-3'; and human RLP13a, sense 5'-TAGCTGCCCCACAAAACC-3' and antisense 5'TGCCGTCAAACACCCTTGAGA-3'. Each sample was analyzed in duplicate using the $\mathrm{IQ}^{\mathrm{TM}}$-Cycler (Bio-Rad). As negative control, the same genes were evaluated in fibroblast extracts. The PCR amplification was related to a standard curve ranging from $10^{-11} \mathrm{M}$ to $10^{-14} \mathrm{M}$. Data are normalized for the expression of the housekeeping gene RLP13a.

Flow cytometry analysis of EPCs. A volume of $100 \mu 1$ of peripheral blood was incubated for $15 \mathrm{~min}$ in the dark at $4^{\circ} \mathrm{C}$ with FITC-conjugated monoclonal antibody against CD34 (Milteny Biotech), and phycoerythrin-conjugated monoclonal antibody against AC133 (Milteny). Related FITC- or PElabeled isotype control (BD) were used as controls. After these incubations, red cells were lysed (FACS Lysing Solution, Beckton Dickinson) for $15 \mathrm{~min}$ at room temperature, washed and fixed with $2 \%$ paraformaldehyde for $15 \mathrm{~min}$. Each analysis included 350,000 events. Only the AC133 positive cells located in the gate of the CD34 bright positive cells were counted.

Statistical analysis. Categorical variables were compared using the non-parametric tests Mann-Whittney or Kruskal Wallis. Spearman rank correlation coefficient were used to calculate the correlation between the number of e-CFU and the other parameters. ANOVA multivariate linear regression stepwise analysis was performed to exclude the influence of other clinical conditions on HDL actions. The data with a $\mathrm{P}<0.05$ were deemed as statistically significant. 


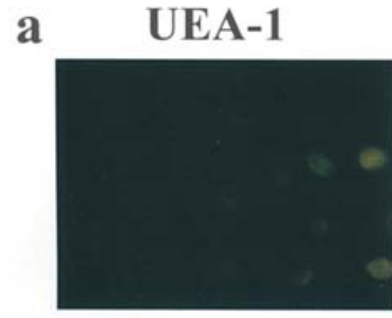

diO-acLDL

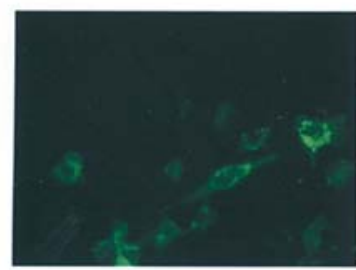

CD31

b

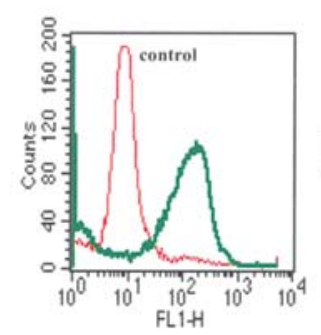

VE-cadherin

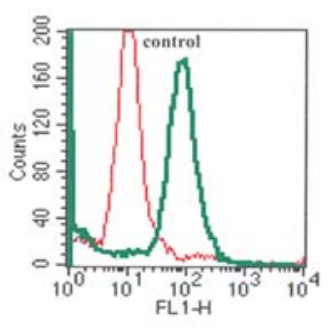

KDR

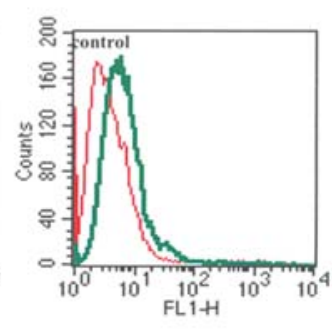

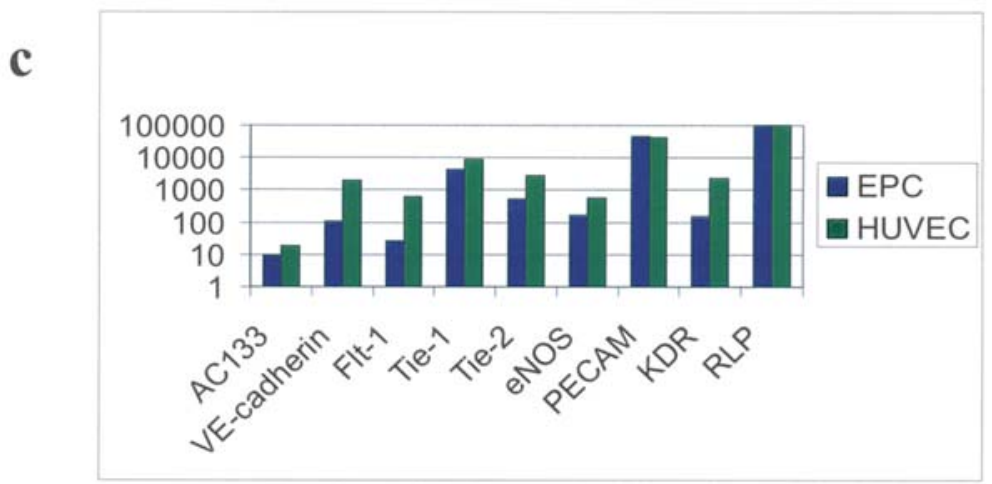

Figure 1. Phenotype characterization of e-CFU-derived cells. Cells were incubated with (a) Dil-acLDL (2.4 $\mu \mathrm{g} / \mathrm{ml})$ at $37^{\circ} \mathrm{C}$ for $1 \mathrm{~h}$, fixed with $2 \%$ paraformaldehyde, and incubated with fluorescein isothiocyanate (FITC)-labeled Ulex Europeus agglutinin I (UEA-1, $10 \mu \mathrm{g} / \mathrm{ml})$ for $1 \mathrm{~h}$. Positive cells were detected by fluorescence microscopy. (b) Expression of CD31, KDR and VE-cadherin evaluated in FACS analysis. (c) mRNA expression of endothelial specific marker: eNOS/NOS3, KDR, VE-cadherin, PECAM-CD31, Flt-1, Tie-1, Tie-2 and AC133, evaluated by real-time quantitative PCR in HUVEC and in e-CFU cells. Data are corrected for the expression of the housekeeping gene RLP13a. Data are expressed as number of relative copies assuming as 100,000 those of the housekeeping gene RLP13a. Data are representative of one of three separate similar experiments.

\section{Results}

Twenty-four patients presenting with a relatively large range of lipidemia (mean LDL plasma level: $3.18 \pm 0.778 \mathrm{mmol} / \mathrm{l}$, range 1.70-4.61; mean HDL plasma level: $1.36 \pm 0.37 \mathrm{mmol} / \mathrm{l}$, range 0.77-2.35; mean triglycerides plasma level: $1.8 \pm 1.3 \mathrm{mmol} / \mathrm{l}$, range 0.6-4.9; mean total cholesterol/HDL cholesterol ratio:

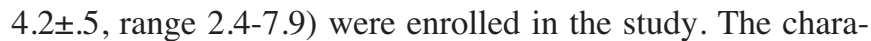
cteristics of the patients are summarized in Table I.

The number of circulating EPCs was evaluated as the number of e-CFU growth after a 7-day culture of the mononuclear fraction. The number of e-CFU is believed to reflect the number of EPCs present in the mononuclear cell sample (16). The range of e-CFU observed, as the average of 6 observations, ranged between 1.3 to 35.6 for million of mononuclear cells seeded.

The endothelial phenotype of the cells originating from the e-CFU was confirmed by their co-positivity to $\mathrm{DiO}$-acetylatedLDL and fluorescein isothiocyanate (FITC)-labeled Ulex Europeus agglutinin, and for their positivity to VEGFR-2/ Flk-1/KDR, PECAM/CD31, VE-cadherin and eNOS, evaluated both in FACS analysis and in real-time PCR (Fig. 1). As a control, we studied mRNA expression of the same genes in fibroblast extracts; a very low expression of these genes was detected, indicating a good sensitivity of the procedure (data not shown).

The global cardiovascular risk (GCR), calculated according to the Framingham score (mean 20.3 \pm 12.8 , range 2-36.3), correlated with the number of e-CFU observed in each patient ( $\mathrm{r}=-0.59, \mathrm{P}=0.009)$ (Fig. 2). HDL cholesterol levels, trigly- cerides and total cholesterol/HDL cholesterol ratio, all significantly related to the number of e-CFU (respectively $\mathrm{r}=0.62, \mathrm{P}=0.006 ; \mathrm{r}=-0.54, \mathrm{P}=0.019 ; \mathrm{r}=-0.61, \mathrm{P}=0.007$ ) (Fig. 2). LDL cholesterol levels did not correlate with the number of e-CFU ( $\mathrm{r}=-0.29 \mathrm{P}=0.26)$. Multivariate linear regression stepwise analysis excluded the influence of other variables such as blood pressure, glycemia, smoking, body weight and age, in determining the HDL cholesterol level correlation with the number of e-CFU observed. This correlation also remained significant when corrected for LDL, triglycerides and total cholesterol/HDL cholesterol ratio.

We next addressed whether also the number of the CD $34^{+} / \mathrm{AC} 133^{+}$progenitor cells correlated with the clinical parameters analyzed. The number of $\mathrm{CD} 34^{+} / \mathrm{AC} 33^{+}$cells (mean $0.057 \pm 0.049 \%$, range $0.011-0.251 \%$ ), as determined by the FACS analysis, correlated neither with HDL, LDL cholesterol, triglycerides, total cholesterol/HDL cholesterol ratio $(\mathrm{r}=-0.07, \mathrm{r}=0.22, \mathrm{r}=0.045, \mathrm{r}=0.075)$ nor with the number of e-CFU ( $r=-0.24)$.

As plasma HDL and VLDL correlated with the number of e-CFU, we investigated in vitro the effects of $\mathrm{HDL}_{3}, \mathrm{VLDL}$ and LDL on e-CFU formation. An equal number of mononuclear cells was seeded on fibronectin coated plates (and therefore the same amount of EPCs), in the presence of increasing concentration of HDL, VLDL and LDL. The number of e-CFU present after 7 days of culture was analyzed. At concentrations of 25,50 and $100 \mu \mathrm{g} / \mathrm{ml}$, VLDL reduced by $64 \pm 10.39 \%$, by $52.7 \pm 12.23 \%$ and by $49.3 \pm 20.11 \%$ respectively the number of e-CFU observed $(\mathrm{P}=0.001, \mathrm{P}=0.007, \mathrm{P}=0.05)$. LDL, at concentrations of 250 and $500 \mu \mathrm{g} / \mathrm{ml}$, reduced by 

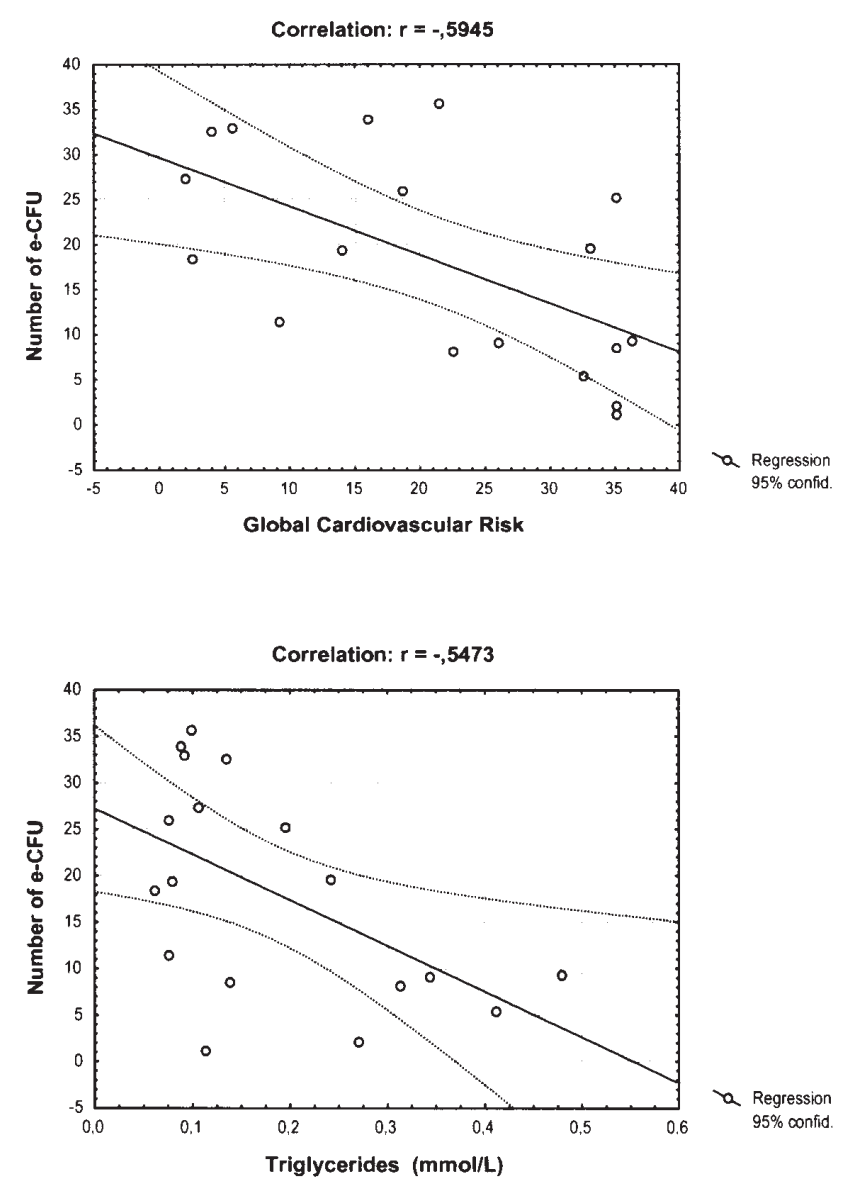
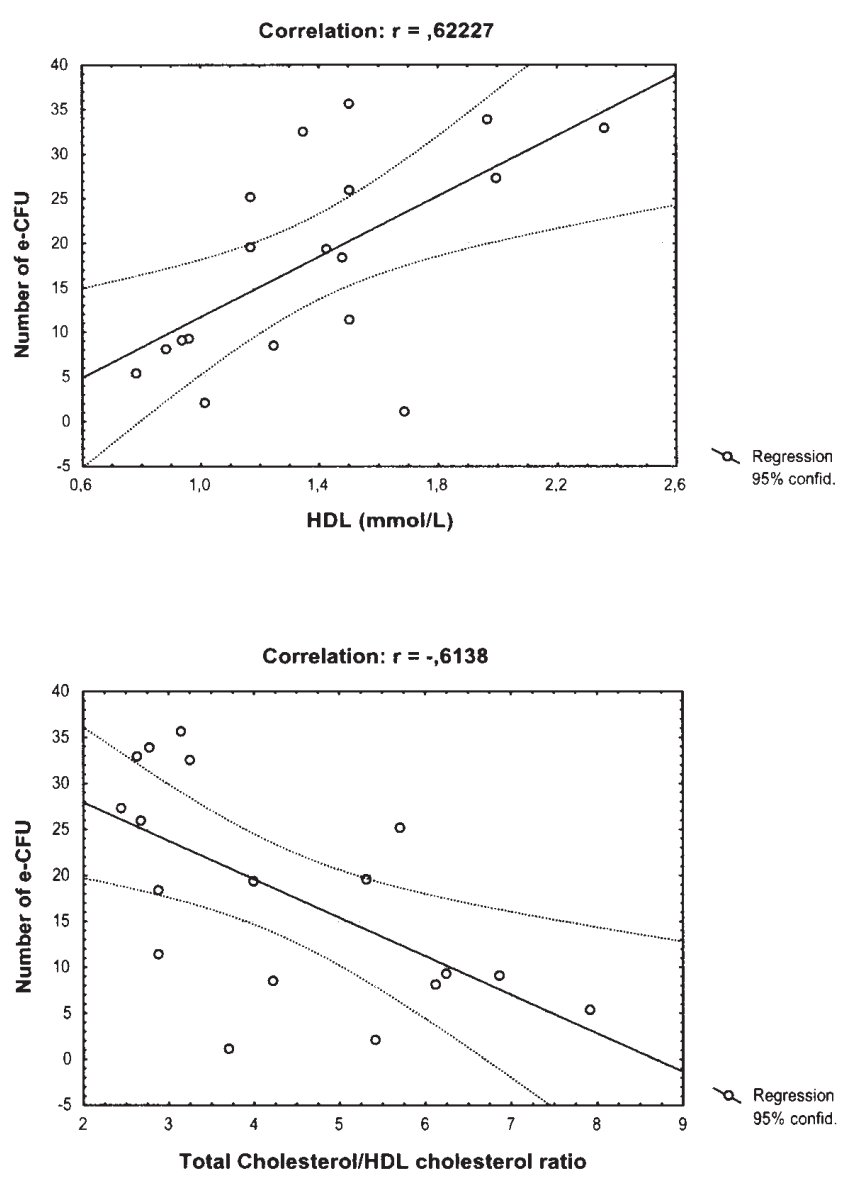

Figure 2. Correlation between the number of e-CFU observed in each patient with the cardiovascular global risk (GCR), HDL plasma levels, triglyceride plasma levels and total cholesterol/HDL cholesterol ratio.

$71.1 \pm 13.14 \%$ and by $69.7 \pm 10.58 \%$ the number of e-CFU $(\mathrm{P}=0.003, \mathrm{P}=0.001)$. Incubation with $\mathrm{HDL}_{3}$ induced a moderate, non-significant, increase only at the lower concentrations (3 and $30 \mu \mathrm{g} / \mathrm{ml}$ ) (Fig. 3).

\section{Discussion}

Endothelial dysfunction is induced by a number of cardiovascular risk factors; this impairment reflects an ongoing injury, and is predictive of cardiovascular events (17).

The mechanisms of injury-repair is still debated, however recent evidence points to a role for circulating progenitor cells (18). Low levels of EPCs were found in patients with increasing cardiovascular risk, the possibility that high levels of risk factors, that modulate oxidative stress, nitric oxide synthesis and/or activity, or other processes, may influence the mobilization or half-life of EPCs has been put forward. In agreement, the reduction of the levels of risk factors, such as LDL reduction by statins, results in an increase of circulating EPCs (6). In addition, Hill et al demonstrated a good correlation between EPCs and endothelial function (5). The same authors also showed that the main cardiovascular risk factors impacted on circulating EPCs levels with a noticeable outlier, HDL cholesterol. Scarce data are available in literature on the correlation between plasma lipid and lipoproteins and the circulating EPCs number, and not all the types of approaches gave the same results: for instance, Vasa et al (4) reported no correlation for total and LDL cholesterol when EPCs were determined in culture, while LDL and total cholesterol were strongly, inversely, relate to the number of EPCs evaluated as $\mathrm{CD}^{+} 4^{+} / \mathrm{KDR}^{+}$cells. Similarly, Chen et al (11) showed an inverse correlation with total and LDL cholesterol, but not with HDL or plasma triglycerides. Eizawa et al however, found no effect of hyperlipemia on CD34+ cell number (19).

We selected the e-CFU procedure to address this issue. In our male population we detected a significant inverse correlation between the estimated number of circulating EPCs and the global cardiovascular risk. Neither total, nor LDL cholesterol related to circulating EPCs, while plasma levels of HDL cholesterol and triglycerides were strongly related to the e-CFU number.

The reasons for these discrepancies are unclear, differences in the population size and characteristics may play a role. For instance, the range of plasma cholesterol, LDL cholesterol, triglycerides and HDL cholesterol is certainly wider in our study as compared with others. We deliberately selected this approach to cover a range of conditions. Moreover, such an approach should have increased the possibility of detecting a correlation with a given parameter, if present. This might have contributed to the detection of the relation of e-CFU with HDL and triglycerides.

Circulating $\mathrm{CD} 34^{+} / \mathrm{AC} 133^{+}$cells are believed to be a precursor of e-CFU, and EPCs are derived from the former (20). We aimed at evaluating whether the number of $\mathrm{CD}^{2} 4^{+} /$ 

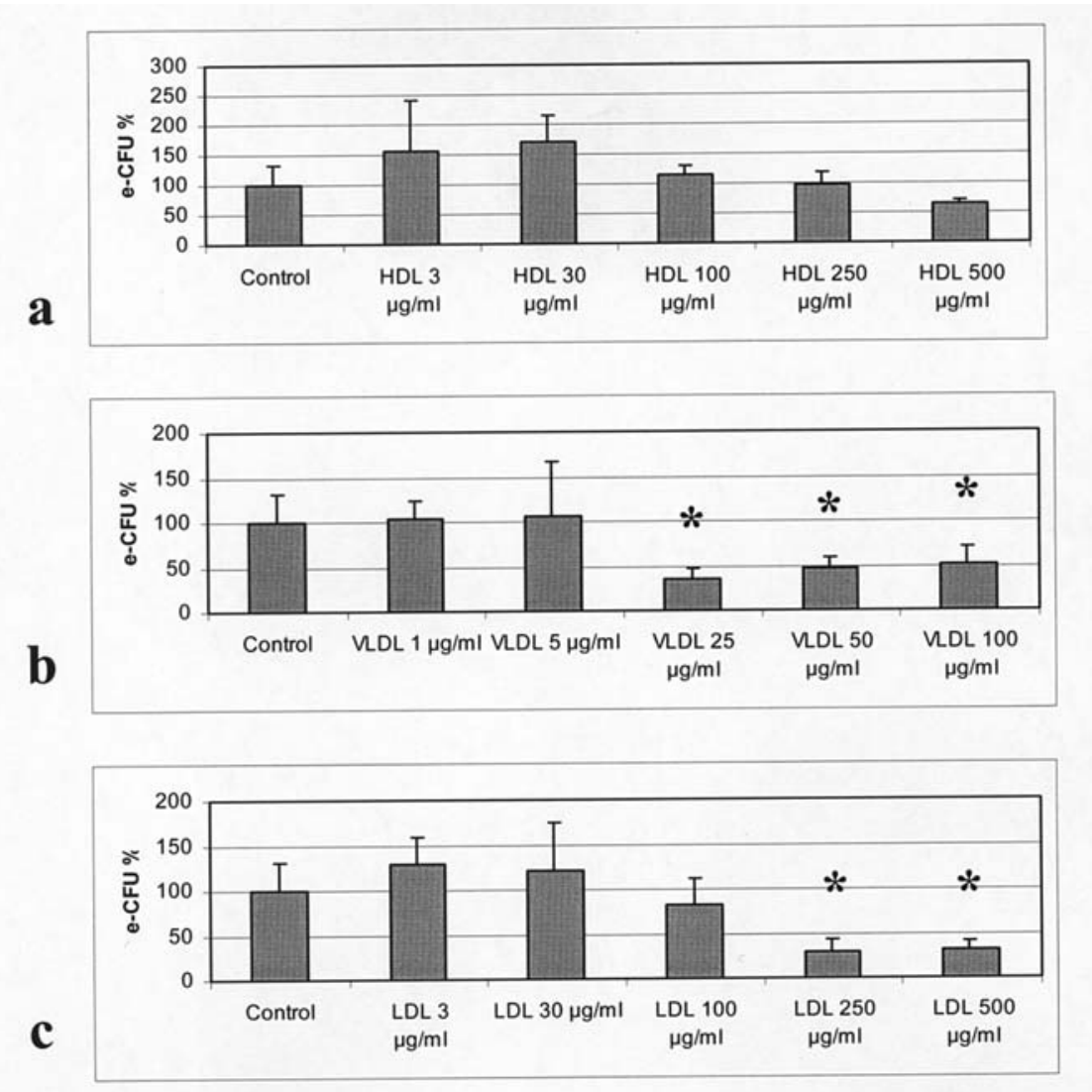

Figure 3. Effect of isolated $\mathrm{HDL}_{3}, \mathrm{VLDL}$ and LDL on e-CFU isolation. One million of mononuclear cells were seeded in fibronectin coated wells and cultured for 7 days without or with $\mathrm{HDL}_{3}(3,30,100,250,500 \mu \mathrm{g} / \mathrm{ml})$, VLDL $(1,5,25,50,100 \mu \mathrm{g} / \mathrm{ml}), \mathrm{LDL}(3,30,100,250,500 \mu \mathrm{g} / \mathrm{ml})\left({ }^{*} \mathrm{P}<0.05\right)$. Data are representative of one of three separate similar experiments.

$\mathrm{CD}_{133^{+}}$cells predicted the e-CFU detected in vitro. Vasa et al found no association for $\mathrm{CD} 34^{+}, \mathrm{CD} 133^{+}$or double positive cells with the main risk factor for CVD, or the presence of CAD (4), while Eizawa et al found a decrease of the CD34+ cells in CAD subjects (19). Our data are in agreement with the findings of Vasa et al (4). Although the mechanisms by which risk factors for CAD reduce e-CFU remains to be addressed, the present data support a specific effect of risk factors on the e-CFU forming activity. We cannot rule out, however, that $\mathrm{CAD}$ negatively impacts on $\mathrm{CD} 34^{+}$cells as no CAD subjects were enrolled in the study.

Several possibilities for explaining the above findings exist, including selective cell death. Several risk factors may induce oxidative stress, a know inductor of apoptosis, or interfere with intracellular signals that are key to the promotion of e-CFU (18). Cytokines such as VEGF or GMCSF may contribute to this effect (3). The burden of risk factors best predicts the decrease of e-CFU suggesting a general mechanism of cellular impairment (5). Our data, therefore, raise the question whether a 'functional' assay, such as e-CFU formation, may represent a better approach to the evaluation of EPC bearing the potential of promoting endothelial 'repair'. The relation between e-CFU and HDL, a finding not previously reported, is in line with this contention.

On the other hand, the fact that in vitro HDL does not promote e-CFU formation suggest that the effect of plasma levels of HDL is related to the total and complex metabolic function exerted by HDL in vivo. In the other hand, the effects observed in vitro with VLDL and LDL suggest a direct role on e-CFU formation.

Our observations raise the question as to whether the lipid environment plays a role in modulating the commitment of circulating $\mathrm{CD} 4^{+} / \mathrm{CD} 133^{+}$cells towards a 'functional' state. HDL cholesterol levels apparently play a significant role in these complex cellular modifications in vivo. Further work is required to address these issues.

\section{Acknowledgements}

This work was supported by the grant: F.I.R.B no. RBNE 01HLAK_006 to A.L.C.

\section{References}

1. Asahara T, Murohara T, Sullivan A, Silver M, van der Zee R, Li T, Witzenbichler B, Schatteman G and Isner JM: Isolation of putative progenitor endothelial cells for angiogenesis. Science 275: 964-970, 1997

2. Rafii S and Lyden D: Therapeutic stem and progenitor cell transplantation for organ vascularization and regeneration. Nat Med 9: 552-556, 2003.

3. Hristov M, Erl W and Weber PC: Endothelial progenitor cells: mobilization, differentiation and homing. Arterioscler Thromb Vasc Biol 23: 1185-1189, 2003.

4. Vasa M, Fichtlscherer S, Aicher A, Adler K, Urbich C, Martin H, Zeiher AM and Dimmeler S: Number and migratory activity of circulating endothelial progenitor cells inversely correlate with risk factors for coronary artery disease. Circ Res 89: E1-E7, 2001. 
5. Hill JM, Zalos G, Halcox JP, Schenke WH, Waclawiw MA, Quyyumi AA and Finkel T: Circulating endothelial progenitor cells, vascular function and cardiovascular risk. N Engl J Med 348: 593-600, 2003.

6. Vasa M, Fichtlscherer S, Adler K, Aicher A, Martin H, Zeiher AM and Dimmeler S: Increase in circulating endothelial progenitor cells by statin therapy in patients with stable coronary artery disease. Circulation 103: 2885-2890, 2001

7. Tepper OM, Galiano RD, Capla JM, Kalka C, Gagne PJ, Jacobowitz GR, Levine JP and Gurtner GC: Human endothelial progenitor cells from type II diabetes exhibit impaired proliferation, adhesion and incorporation into vascular structures. Circulation 106: 2781-2786, 2002.

8. Vasa M, Fichtlscherer S, Aicher A, Adler K, Urbich C, Martin H, Zeiher AM and Dimmeler S: Number and migratory activity of circulating endothelial progenitor cells inversely correlate with risk factors for coronary artery disease. Circ Res 89: E1-E7, 2001.

9. Kondo T, Hayashi M, Takeshita K, Numaguchi Y, Kobayashi K, Iino S, Inden Y and Murohara T: Smoking cessation rapidly increases circulating progenitor cells in peripheral blood in chronic smokers. Arterioscler Thromb Vasc Biol 24: 1-6, 2004.

10. Lambiase PD, Edwards RJ, Anthopoulos P, Rahman S, Meng YG, Bucknall CA, Redwood SR, Pearson JD and Marber MS: Circulating humoral factors and endothelial progenitor cells in patients with differing coronary collateral support. Circulation 109: 2986-2992, 2004

11. Chen JZ, Zhang FR, Tao QM, Wang XX, Zhu JH and Zhu JH: Number and activity of endothelial progenitor cells from peripheral blood in patients with hypercholesterolaemia. Clin Sci 107: 273-280, 2004.

12. Lamarche B, Lemieux I and Despres JP: The small, dense LDL phenotype and the risk of coronary heart disease: epidemiology, pathophysiology and therapeutic aspects. Diabetes Metab 25: 199-211, 1999.
13. Gaw A: HDL-C and triglyceride levels: relationship to coronary heart disease and treatment with statins. Cardiovasc Drugs Ther 17: 53-62, 2003

14. Havel RJ, Eder HA and Bragdon JH: The distribution and chemical composition of ultracentrifugally separated lipoproteins in human serum. J Clin Invest 34: 1345-1353, 1955.

15. Lowry OH, Rosebrough NJ, Farr AL and Randall RJ: Protein measurement with the Folin reagent. J Biol Chem 193: 265-275, 1951.

16. Basu SK, Goldstein JL, Anderson GW and Brown MS: Degradation of cationized low density lipoprotein and regulation of cholesterol metabolism in homozygous familial hypercholesterolemia fibroblasts. Proc Natl Acad Sci USA 73: 3178-3182, 1976.

17. Schmidt-Lucke C, Rossig L, Fichtlscherer S, Vasa M, Britten M, Kamper U, Dimmeler S and Zeiher AM: Reduced number of circulating endothelial progenitor cells predicts future cardiovascular events: proof of concept for the clinical importance of endogenous vascular repair. Circulation 111: 2981-2987, 2005.

18. Urbich C and Dimmeler S: Endothelial progenitor cells. Characterization and role in vascular biology. Circ Res 95: 343-353, 2004.

19. Eizawa T, Ikeda U, Murakami Y, Matsui K, Yoshioka T, Takahashi M, Muroi K and Shimada K: Decrease in circulating endothelial progenitor cells in patients with stable coronary artery disease. Heart 90: 685-686, 2004.

20. Peichev M, Naiyer AJ, Pereira D, Zhu Z, Lane WJ, Williams M, Oz MC, Hicklin DJ, Witte L, Moore MA and Rafii S: Expression of VEGFR-2 and AC133 by circulating human CD34+ cells identifies a population of functional endothelial precursors. Blood 95: 952-958, 2000. 